\title{
Traditional Uses, Pharmacological Action and Phytochemical Analysis of Carissa carandas Linn.:A Review
}

Tamrat Tesfaye* and Yesudass Dominic Ravichadran

Department of Chemistry, College of Natural and Computational Science, Wollega University, Nekemte, Ethiopia

*Corresponding author: Tamrat Tesfaye, Department of Chemistry, Wollega University, Nekemte, Ethiopia, Tel: 251911862871; E-mail: tamrattesfaye2641@gmail.com

Received: July 10, 2018; Accepted: July 20, 2018; Published: August 01, 2018

Copyright: (c) 2018 Tesfaye T, et al. This is an open-access article distributed under the terms of the Creative Commons Attribution License, which permits unrestricted use, distribution, and reproduction in any medium, provided the original author and source are credited.

\begin{abstract}
Starting from immemorial time; peoples traditionally used herbs and plants to treat different human and animals ailments. This initiated scientists to investigate on traditional medicinal plants and herbs for biological activities by checking through bioassay and then isolating the bioactive constituents from biologically active medicinal plants and herbs. The different parts of Carissa carandas have been used for various human ailments. It has been used by traditional healers in the treatment of scabies, intestinal worms, pruritus, biliousness, snake-bite/poisoning, astringent, anemia, stomachache, diarrhea, rheumatism, earache, anthelmintic, female libido, hyperdipsia, anorexia, intermittent, mouth ulcer and sore throat, syphilitic pain, burning sensation fever, biliary dysfunction and also used as appetizer, antimicrobial, anti-fungal, analgesic, anti-inflammatory and anti-scorbutic. Its biological activities have been reported by different researchers as hepatoprotective, neuropharmacological, anticancer, antioxidant, anticonvulsant, antiulcer, anthelmintic, analgesic, anti-inflammatory, cardiovascular, antinociceptive, anti-diabetic, anti-pyretic, cardiotonic, histamine releasing, DNA damage inhibition, constipation, anti-diarrheal, antihyperlipidemic, antibacterial, antiviral, cytotoxic potential and diuretic. Its phytochemical constituents which impart medicinal value to the plant was reported as alkaloids, carbohydrates, glycosides, unsaturated sterols, phenolics, saponins, flavonoids, steroids, triterpenoids, tannins, proteins, cardiac glycosides, phytosterol, phlobatannins, leucoanthocyanin, chalcones, coumarin, anthracyanin, emodin, minerals acids, vitamins and anthraquinone glycosides. So far 14 compounds have been isolated from roots, 40 compounds from fruits and 19 compounds from leafs. These compounds include phenolic, alkaloids, sterols, terpenoids, simple acids, simple ester, sesquiterpenes, carboxylate, amino acids, glucose and galactose, sterols glycosides, phenolic lignin. Hence we reviewed the traditional uses, extraction methods, pharmacological uses and phytochemical constituents of Carissa carandas.
\end{abstract}

Keywords: Carissa carandas; Traditional uses; Pharmacological uses; Phytochemical constituents

\section{Introduction}

Carissa carandas (C. carandas) is a perennial [1] flowering [2,3] and shrub with strong thorns in pairs [4] belong to the dogbane family Apocynaceae and found to be widely distributed throughout subtropical and tropical region of Pakistan [4,5], India [4,6], Bangladesh, Srilanka, Java, Malaysia, Myanmar and Nepal [4]. The plant has been cultivated for hedging around home gardens to prevent garden vegetables from damaging by animals $[5,6]$ and also used as ornamental due to its beautiful cherry-like fruits [6]. It is an evergreen plant which is a hardy, droughttolerant plant that thrives well in a wide range of soils. Its common name is Koromcha in Bangladesh and Karanda in English. Its botanical name was recently changed to C. congesta Wight (syn. C. carandas Auct formerly widely shown as $C$. carandas L.) $[7,8]$. Starting from immemorial time; peoples traditionally used herbs and plants to treat different human and animals ailments. It has been studied that the ethanolic extract of the C. carandas root has been reported for its histamine releasing activity used to assess the intensity of snake poisoning [9]. The phytochemical constituents in it had led to the isolation of several substances including betulinic acid, oleanoic acid [5], $\beta$-sitosterol, lupeol, mixture of cardenolides, carissone and carindone. Its fruits have been used as a dietary supplement or medicinal food for centuries and are of increasing importance to consumers [9].
Recent studies revealed that a number of plant products including polyphenols, terpenes, flavonoids, alkaloids and various plant extracts exert an antioxidant action, anti-inflammation, anti-malaria and others. There is evidence regarding an association between individuals who have a diet rich in fresh fruits and vegetables, and the decreased risk of cardiovascular diseases due to its pharmacological activities such as antioxidant, antiviral and certain types of cancer healing properties [10]. However, traditionally used medicinal plants still await such screening. On the other hand, the medicinal properties of plants have also been investigated in the light of recent scientific advancements throughout the world, due to their potent pharmacological properties, low toxicity and economic viability.

Nowadays, a great deal of effort being expanded to find effective and valuable bioactive chemical constituents for the treatment of different human ailments. This review gives good information on the traditional uses, extraction methods, pharmacological uses and phytochemical constituents of $C$. carandas Linn (Figure 1). 


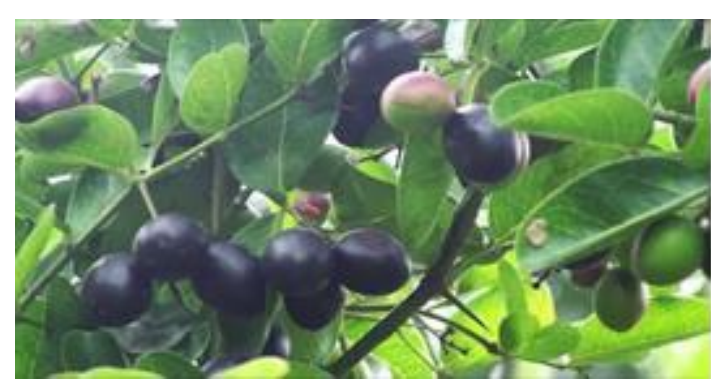

Figure 1: Carissa carandas Linn.

\section{Taxonomy}

Kingdom: Plantae

Order: Gentianales

Class: Angiosperms

Family: Apocynaceae

Sub-class: Eudicots

Superorder: Asterids

Genus: Carissa

Species: carandas

\section{Carissa carandas description}

Carissa carandas commonly known as karonda is an evergreen deciduous plant, generally $2-4 \mathrm{~m}$ tall shrub of the dogbane family Apocynaceae. The stem is rich in white latex and the branches contain sharp spines. Flowers are small, measuring $3-5 \mathrm{~cm}$ in diameter, with white colors. The fruit is a berry, which is formed in clusters of 3-10 fruits, with 5-1 hard angles curving upwards, glabrous with five to seven wings, fibrous and woody. The fruit is globose to broad ovoid in shape with many seeds. Young fruits are pinkish white and become red to dark purple when ripe. Ripe fruit color varies from white, green and pinkish red depending on the genotype. Seed 3-5 per fruit, blankish brown, flat, elliptical and light in weight. Flowering starts in the month of January- February and fruits mature in May-June. Fruits are generally harvested at immature stage for vegetable purpose, fully ripen fruits are consumed fresh or processed [11,12]. The leaves are oblong and conical, 4-6 inch long and 2-3 inch wide, green on the top and brown below. If the leaves or stems are injured, the white milky sap is seen, which is characteristic of this group of plants. Flowers are white or yellowish flowers are found in groups. The bark is smooth gray. The bark is thick, soft and of red color from inside [13].

\section{Traditional use of Carissa carandas Linn}

Carissa carandas produces beautiful and attractive berry-sized fruits that are commonly used as a condiment or additive to Indian pickles and spices. C. carandas is edible and used as appetizer, and the fruit is pickled before it gets ripened [14]. Ripe $C$. carandas fruit has pectin and used for making pickle, jelly, jam, squash, syrup, tarts and chutney $[6,14]$, which has commercial value [6]. The unripe fruits have astringent taste owning to rich in iron and vitamin $\mathrm{C}$ which has anti- scorbutic property and can be used for the treatment of anemia [4,12,14-16].

In the traditional system, it is known to treat different human ailments as an astringent, appetizer, antipyeretic in stomach disorders, rheumatism, treat brain disease [7], anthelmintic, cardiotonic and lowering blood pressure [1]. The stem part of plant is used to strengthen tendons $[2,3,14,17]$. Fruits of $C$. carandas has been used to treat various human ailments such as: colic, oedema, hepatomegaly, splenomegaly, indigestion, cardiac diseases, amenorrhoea, and it is useful in treating of brain anorexia disease [15,18]. It is also useful for the treatment of fever $[6,15,19]$, sour, acrid, appetite loss, antipyretic, piles, and act as nervine to calm the nervous disorder and having antiscorbutic properties used to treat anemia [15]. Further, it has been used in treatment of malaria, epilepsy, pain relief, myopathic spasms, dog bite, cough, colds, itches and leprosy [19], skin infections $[2,3,14]$ female libido, intestinal worms, antimicrobial, antifungal $[14,16]$, liver dysfunction, to counteract the putrefaction of blood $[6,8]$, rheumatoid arthritis [18], biliousness, stomachache, diarrheal, anthelmintic and as astringent, analgesic and anti-inflammatory. Its leaves are remedy for fevers, diarrheal, earache, syphilitic pain $[2,3,8]$ and snake-bite/ poisoning [20]. The root part of it has been used to improve digestion, anthelmintic, antimicrobial $[4,6]$, stomach disorder, intestinal worms, scabies, diabetic, ulcer, pruitis [21] and also used to reduce high blood pressure [19].

\section{Extraction methods}

This review is used to identify the good extraction techniques practice that has been used by different investigators in order to analysis pharmacological and phytochemical constituents of the different parts of $C$. carandas plant and to give direction for future work on this plant.

The pulverized leaves of the plant was extracted with different solvents by different investigators using various extraction methods such as: methanol $[3,19,22]$, ethanol $(80 \%)[4,7]$, ethanol (95\%) [16], ethanol and water (1:1) [12], cold aqueous [2,23], methanol (80\%), ethanol (70\%) and ethyl acetate (80\%) [2] in a soxhlet extractor $[3,7,16,22]$, maceration $[2,4,12,23]$, shaker [19]. The leaves and fruit part of the plant were extracted with water, chloroform, ethyl acetate in shaker [15]. The coarse powder of the roots were extracted with ethanol (50\%), methanol [18], ethanol (95\%), aqueous [18,24], pet ether $(60-80 \%)$, chloroform, ethyl acetate and ethanol [21] solvents in maceration $[18,24]$ and Soxhlet extractor $[21,24]$. The powdered fruits and root of the plant were extracted with ethanol using Soxlet apparatus [25]. The powdered fruit was extracted with methanol [26-28], ethanol, n-hexane [9] using maceration [26,28] and Soxlet apparatus $[9,27]$. The overall evaluation of this review shows that alcohol (methanol and ethanol) extraction followed by aqueous is the appropriate solvent for the extraction of root, leaf, and fruit of $C$. carandas in order to get more phytochemical constituents which is biologically active molecules using maceration with magnetic stirring or shaking techniques. In general, polar solvents are more effective in the extraction of bioactive molecules from $C$. carandas Linn. A convenient and frequently used procedure is sequential solvent extraction. A first step, with dichloromethane, for example, will extract flavonoid aglycones and less polar material. A subsequent step with an alcohol will extract flavonoid glycosides and polar constituents. Certain flavanone and chalcone glycosides are difficult to dissolve in methanol, ethanol, or alcohol-water mixtures. Flavanone solubility depends on the $\mathrm{pH}$ of water-containing solutions. Flavan-3-ols 
(catechins, proanthocyanidins, and condensed tannins) can often be extracted directly with water. However, the composition of the extract does vary with the solvent whether water, methanol, ethanol, acetone, or ethyl acetate is used. For example, it is claimed that methanol is the best solvent for catechins and 70\% acetone for procyanidins.

Anthocyanins are extracted with cold acidified methanol. The acid employed is usually acetic acid (about 7\%) or trifluoroacetic acid (TFA) (about 3\%). The use of mineral acid can lead to the loss of attached acyl groups [29].

\section{Pharmacological use of Carissa carandas Linn.}

Carissa carandas is known to possess wide range of phytochemical constituents that imparts vast medicinal value to the plant. The pharmacological use of the plant has been studied by many investigators using in-vitro and in-vivo approaches and discovered different remedial action for human ailments.

\section{Anticonvulsant activity}

In the study of anticonvulsant activity, the ethanolic extract of $C$. carandas root in the interval of $100-400 \mathrm{mg} / \mathrm{kg}$ showed significant reduction on electrically and chemically induced seizures. But only 200 and $400 \mathrm{mg} / \mathrm{kg}$ of the extract conferred protection $(25 \%$ and $50 \%$, respectively) on the mice. The same doses saved the animals under investigation from pentylenetetrazole-induced tonic seizures and significantly delayed the onset of tonic seizures produced by picrotoxin, and N-methyl-dl-aspartic acid [6].

\section{Hepatoprotective effect}

The ethanolic extract of root was tested for its hepatoprotective activity at 100,200 and $400 \mathrm{mg} / \mathrm{kg}$ against $\mathrm{CCl}_{4}$, paracetamol and ethanol- induced hepatotoxicity in rat by decreasing the activities of serum marker enzymes, bilirubin, alkaline phosphate, total protein, total cholesterol and lipid peroxidation and showed significant hepatoprotective activity. It also increased significantly the levels of uric acid, glutathione, super oxide dismutase, catalase, and protein in a dose dependent manner that was confirmed by the decrease in the total weight of the liver and histopathological examination. The ethanol and aqueous extracts at a dose level of $100 \mathrm{mg} / \mathrm{kg}$ and 200 $\mathrm{mg} / \mathrm{kg}$ produced significant hepato-protection by decreasing serum transaminase (serum glutamic pyruvic transaminase and serum glutamic oxaloacetic transaminase), alkaline phosphate, bilirubin and lipid peroxidation, while significantly increased the levels of liver glutathione, and serum protein $[6,9,30]$.

The ethanol and aqueous extracts of roots was evaluated against ethanol induced hepatotoxicity in rats for its hepatoprotective effects. Its liver function, serum lipid profile, levels of lipid peroxidation and the activity of liver antioxidant enzyme glutathione were established at a dose level of 100 and $200 \mathrm{mg} / \mathrm{kg}$. The effect of extract produced significant hepatoprotection by decreasing serum transaminase bilirubin and lipid peroxidation, while it significantly increased the levels of liver glutathione and serum protein [24].

\section{Antimicrobial activity}

The pet ether and methanolic extracts of leaf and stem showed better antibacterial activities against both gram positive and gramnegative bacteria. It indicates the presence of broad spectrum antibiotic compounds [1]. The methanolic extract of $C$. carandas leaf exhibited higher degree of antibacterial activity against Staphylococcus aureus, followed by ethyl acetate extract against Escherichia coli compared to tetracycline which are responsible for cause of gut infection, stomachache and diarrhea [2]. The root extract has been used by tribal healers for antimicrobial purpose confirms the test $[4,6]$.

\section{Antiviral activity}

The ethanolic extract of $C$. carandas fruits possess effective antiviral activity against polio virus HIV-1 at $6 \mu \mathrm{g} / \mathrm{ml}$, sindbis virus at $3 \mu \mathrm{g} / \mathrm{ml}$ and herpes simplex virus at $12 \mu \mathrm{g} / \mathrm{ml}$ [9].

\section{Anti-diabetic activity}

It was investigated that aqueous extract of $C$. carandas on alloxan induced and normoglycemic Wister rats significantly $(\mathrm{p}<0.05)$ decreased the blood glucose levels of alloxan diabetic Wister rats at doses interval of $500-1000 \mathrm{mg} / \mathrm{kg}$ at 4, 8 and $24 \mathrm{hrs}$. Furthermore, the methanol extracts on alloxan induced diabetic rats significantly lowered the elevated blood glucose levels at dose level of $400 \mathrm{mg} / \mathrm{kg}$ orally after $24 \mathrm{hrs}$ compared to diabetic control. This is due to the presence of polyphenol and flavonoid content of the extracts $[6,31]$.

Further, it was evaluated that the methanol extract and its fractions in alloxan induced diabetic rats showed anti-diabetic potential. The investigators reported that the methanol extract and its ethyl acetate soluble fraction have significantly lowered the elevated blood glucose levels at dose level of $400 \mathrm{mg} / \mathrm{kg}$ orally after $24 \mathrm{hrs}$, as compared to diabetic control. Polyphenol content of methanol extract and its ethyl acetate soluble fraction were found to be $15.8 \pm 1.2 \mathrm{mg}$ and $18.55 \pm$ $0.34 \mathrm{mg}$ (gallic acid equivalent/g extract), whereas, flavonoid content of both extracts were $2.92 \pm 0.03 \mathrm{mg}$ and $1.534 \pm 0.30 \mathrm{mg}$ (rutin equivalent/g extract) respectively. The workers concluded that the antidiabetic potential of ethyl acetate fraction over methanol extract is due to its partial purification achieved by fractionation which resulted in increase in degree of polymerization, and segregation of secondary metabolites [32].

Analgesic, anti-inflammatory and antipyretic activities Some investigators reported that ethanol and aqueous extracts from $C$. carandas roots against rodent models showed significant analgesic, anti-inflammatory and antipyretic activities. The ethanol and aqueous extracts from roots of the plant exhibited significant $(\mathrm{p}<0.01)$ analgesic, anti-inflammatory, and antipyretic activities at the doses of 100 and $200 \mathrm{mg} / \mathrm{kg}$ body weight. The workers observed highest percentage of inhibition of abdominal constriction (72.67\%) of ethanol extracts of the plant at a dose of $100 \mathrm{mg} / \mathrm{kg}$ body weight in analgesic activity. Further, the ethanol and aqueous extracts of it reduced the formation of edema induced by carrageenan after 2 hrs significantly $[6-8,23,24]$.

The methanol extract of C. carandas's leaf showed antiinflammatory and anti-pyretic activities. The extract at the dose of 200 $\mathrm{mg} / \mathrm{kg}$ body weight exhibited maximum inhibition of inflammation, i.e., $72.10 \%, 71.90 \%$ and $71.80 \%$ at the end of $3 \mathrm{hrs}$ with histamine, dextran and carrageenan induced rat paw edema respectively compared to indomethacin standard drug. The anti-pyretic activity was evaluated by Brewer's yeast induced pyrexia in albino rats. The extract at the dose of 100 and $200 \mathrm{mg} / \mathrm{kg}$ showed significant antipyretic activity compared to paracetamol at dose $150 \mathrm{mg} / \mathrm{kg}$ [3]. The percentage of inhibition was calculated by using formula,

$\%$ inhibition $=V c-V t / V c \times 100$ 
Where, $\mathrm{Vc}=$ Average paw volume of control;

\section{$\mathrm{Vt}=$ Average paw volume of test}

The methanol extract of $C$. carandas fruit revealed antiinflammatory effects on carrageenan-induced hind paw edema in rats. The extracts were given orally to the rats at a dose of 100,200 , and 400 $\mathrm{mg} / \mathrm{kg}$ body weight and exhibited $33.7,60.95$, and $76.12 \%$ inhibition of paw edema volume when compared with control at $2 \mathrm{hrs}$ respectively [26].

\section{Cardiovascular activity}

Nowadays, cardiovascular disease comprises large number of diseases such as: coronary artery disease, heart attack, heart failure, high blood pressure and stroke that affect the heart and the blood vessels. According to the World Health Organization, it was estimated that the disease causes deaths of approximately 30,000 people each day [33]. The effect of $C$. carandas extract was evaluated on cardiovascular function of normal rats. Intravenous bolus injection of this extract at dose of $45 \mathrm{mg} / \mathrm{kg}$ produced significant $(\mathrm{p}<0.001)$ dose dependent reduction in arterial blood pressure. The $45 \mathrm{mg} / \mathrm{kg}$ dose caused significant $(50.75 \%)$ decrease in mean arterial blood pressure. A significant reduction in heart rate frequency was observed after extract of $C$. carandas injection at a dose of $45 \mathrm{mg} / \mathrm{kg}(\mathrm{p}<0.001)$. The results were comparable with acetylcholine $10^{-4} \mathrm{M}$. It was concluded that the C. carandas ethanol extract possess potent acute hypotensive effect in normal rats. It stimulates the muscarinic receptors located on the endothelial cells of the vasculature. This stimulation results in the release of endothelial-derived relaxing factors or nitric oxide that diffuses to vasculature smooth muscles and causes their relaxation [34]. The ethanolic extract of $C$. carandas roots exhibited cardiotonic activity and lowered the blood pressure. The presence of water soluble glucosides known as odoroside in the plant is responsible for cardiac activities. The extract at dose $45 \mathrm{mg} / \mathrm{kg}$, i.p. caused significant $(50.75 \%)$ decreases in arterial blood pressure $(\mathrm{P}<0.001)$ and the frequency of heart rate was also reduced significantly. It was also found that the ethanol extract of plant possess potent hypotensive effect in normal rats [9].

\section{Adaptogenic activity}

The isolated lanost-5-en-3 $\beta$-ol-21-oic acid (lanostane triterpenoid) from ethanolic extract of $C$. carandas fruit was screened for adaptogenic activity against swimming endurance, anoxia stress tolerance and cyclophosphamide induced immunosuppression model. The levels of $\mathrm{RBC}, \mathrm{Hb}, \mathrm{WBC}$, organ weight and body weight suppressed by cyclophosphamide were evaluated. It was observed that the lanostane triterpenoid in the extract is played great role in increasing the swimming endurance, anoxia stress tolerance and normalized the $\mathrm{RBC}, \mathrm{Hb}$, WBC, affected organ and body weight $(\mathrm{P}<0.05$ and $\mathrm{P}<0.01)$ suppressed by cyclophosphamide. This show that the isolated compound showed significant adaptogenic activity [35].

\section{Anthelmintic activity}

The pet ether (60-80\%), chloroform and ethanolic extract of unripe fruits were tested in in-vitro against earthworm paralysis with various concentrations (50, 100 and $150 \mathrm{mg} / \mathrm{ml}$ ) of the different solvent extracts showed anthelmintic activity. The extract of unripe fruit showed shortest time of paralysis and death of worms at higher dose $(150 \mathrm{mg} / \mathrm{ml})$ of ethanolic, chloroform, and petroleum ether extract, i.e., found to $56.35 /$ minutes, $40 /$ minutes, and 22.35 minutes, respectively compared to piperazine citrate $(15 \mathrm{mg} / \mathrm{ml})$ as standard drug. This indicated that the ethanolic extract possess potent anthelmintic activity than other solvent extracts due to the availability of some important phytochemical constituents in ethanol extract which is absent in the rest solvent extracts $[6,8,9]$. The methanolic extract of leaf showed significant antinociceptive activity and the fresh juice of the leaves of $C$. carandas showed potent anthelmintic activity. In cytotoxicity studies, the methanol leaves extract displayed moderate cytotoxic activity when compared with standard drug, vincristine sulphate [36-41].

\section{Anti-malaria activity}

Malaria is one of the parasitic diseases that affect human health worldwide. This attracted the attention of researchers to investigate on traditional medicinal plants used so far by traditional healers. The methanolic and aqueous extracts of three different parts (leaf, stem bark and fruit) of the plant were tested in in-vitro against Plasmodium falciparum 3D7 strain and showed anti-malarial activity. Both aqueous and methanolic extract exhibited promising anti-malarial activity with minimum inhibition concentration of $\left(\mathrm{IC}_{50}\right.$ ranged between 41.52 and $100 \mu \mathrm{g} / \mathrm{mL}$ ) and ( $\mathrm{IC}_{50}$ ranged between 13.57 and $69.63 \mu \mathrm{g} / \mathrm{mL}$ ) respectively. The cytotoxicity of host cell was also analyzed on MadinDarby canine kidney cell line by using a standard MTT (3-[4,5dimethylthiazole-2-yl]-2,5-diphenyltetrazolium bromide) colorimetric assay test that exposed no cytotoxicity at maximum dose $[6,8,9]$.

\section{Antioxidants and anti-cancer activity}

It was studied that the methanolic extract of $C$. crandas leaf showed significant anti-cancer activity against lung cancer and human ovarian carcinoma cells. The isolated pentacyclic triterpenoid carandinol ( $3 \beta$, $21 \alpha$-dihydroxyisohopane) from the extract of leafs part exhibited significant cytotoxicity to every cell line tested (HeLa, PC-3 and 3T3) in vitro and was relatively more toxic to human cervical cancer (HeLa) cell line [5]. In another investigation, the chloroform, n-hexane and methanol extracts of $C$. carandas fruits showed significant anti-cancer activity on the lung cancer and human ovarian carcinoma cells. It was investigated that the anticancer and antioxidant potentials of the methanolic extract was analyzed by unusual antioxidant enzymes such as catalase, dismutase, superoxide, glutathione transferase and glutathione on MCF-7 cancer lines. It exhibited significant antioxidant activity and fortification of cell death in MCF-7 cell line [9]. The antioxidant activity is mainly due to the presence of ascorbic acid and phenolic compounds. It was reported by another investigator that methanolic extract of the leaf exhibited significant $(\mathrm{P}<0.05)$ antioxidant and DNA damage inhibition potential with dosedependent at $\mathrm{MIC}_{50} 73.1 \mathrm{~g} / \mathrm{mL}$ and $84.031 \mathrm{~g} / \mathrm{mL}$ against 1, 1diphenyl-2-picrylhydrazyl (DPPH) radical scavenging activity and $\mathrm{H}_{2} \mathrm{O}_{2}$ scavenging activity respectively compared to ascorbic acid and gallic acid taken as standards. Optical density of these samples was measured at $517 \mathrm{~nm}$ along with blank where $1 \mathrm{ml}$ methanol with $1 \mathrm{ml}$ DPPH solution was taken. pBR 322 plasmid DNA was saved from free radical-mediated oxidative stress in a DNA damage inhibition assay $[17,36,42]$.

\section{Anti-hyperlipidemic activity}

The ethanol: aqueous (1:1 ratio) extract of leaf also reported to have significant anti-hyperlipidemic activity toward cellular damages caused by hyperlipidemia. Histopathological screening showed that the cellular damaged by hyperlipidemia were healed after treating with 
aqueous-ethanol mixture extract of $C$. carandas leaf. This is the reason why the level of high density lipoprotein is high in blood of rats fed with hypercholesterolaemic diets than controls group. The rats fed on $24 \%$ egg yolk in their diet as well as treated with ethanolic extract of leaf $(1000 \mathrm{mg} / \mathrm{kg})$ was found to cause a significant decrease in high density lipoprotein of hyperlipidaemic, while drug fed rats on $24 \%$ egg yolk in their diet as well as treated with atorvastatin $(0.2 \mathrm{mg} / \mathrm{kg})$ group caused highly significant decrease [12].

\section{Neuropharmacological and diuretic effects}

It was reported that the methanolic extract of leaves was exhibited significant neuropharmacological and diuretic activities. It was confirmed that the methanolic extract of leaves have diuretic activity by the electrolyte loss ratio $\left(\mathrm{Na}^{+} / \mathrm{K}^{+}\right.$excretion ratio was 1.46 and 1.43 at the doses of 200 and $400 \mathrm{mg} / \mathrm{kg}$ respectively) as that of the standard drug furosemide and diuretic agent urea [4].

\section{Anti-nociceptive activity}

The methanolic extract of leaves showed dose-dependent antinociceptive activity and decreased the number of writhing induced by intraperitoneal administration of acetic acid in acetic acid-induced gastric pain model in Swiss albino mice. The result was comparable to the standard pain-killing drug; aspirin. Standard pain-killing drugs like aspirin and paracetamol suffer from the problem of inducing gastric ulceration or hepatotoxicity from over dose or prolonged use. Therefore, newer and more efficacious painkillers can prove to be highly beneficial to human beings [37].

\section{Anti-constipation and anti-diarrhea activity}

It was investigated that ethanolic extract of fruits and roots in rodent models showed significant anti-diarrheal. In the castor oilinduced diarrhoea experiment, the ethanolic fruit extracts produced a marked anti-diarrhoeal effect at doses of 200 and $400 \mathrm{mg} / \mathrm{kg}$ and the extract significantly decreased $(\mathrm{p}<0.05)$ the total number of wet feace produced upon administration of castor oil $(1.1 \pm 0.19$ at $200 \mathrm{mg} / \mathrm{kg}$ and $2.18 \pm 0.14$ at $400 \mathrm{mg} / \mathrm{kg}$ ). The ethanolic extract of root was showed more efficacy $(1.19 \pm 0.08$ at $200 \mathrm{mg} / \mathrm{kg}$ and $2.42 \pm 0.14$ at 400 $\mathrm{mg} / \mathrm{kg}$ ) compared to the control (Saline $5 \mathrm{ml} / \mathrm{kg}$, p.o.) atropine sulphate group $(0.87 \pm 0.03$ at $5 \mathrm{ml} / \mathrm{kg}, \mathrm{p} . \mathrm{o})$. The effect of the highest dose of the ethanolic fruit and root extracts was similar to that of the standard drug $(2.88 \pm 0.13$ at $5 \mathrm{mg} / \mathrm{kg})$. Therefore, it can be assumed that the anti-diarrheal action of the extracts was mediated by an antisecretory mechanism. This was also evident from the inhibition of castor oil-induced fluid accumulation (enteropooling) by the extracts [25] and ethanolic extract of fruits and roots showed extensive anticandidal action [9]. The pharmacological effect of crude extract of C. carandas leaves against constipation and diarrhea investigated using in-vivo on mice, and in-vitro experiments on isolated rabbit jejunum, and guinea pig ileum preparations. The high-performance liquid chromatography fingerprints of the extract exhibited the presence of oleanolic acid, ursolic acid, stigmasterol and $\beta$-sitosterol constituents. It was concluded that these compounds in the crude extract of $C$. carandas is responsible for gut-stimulatory effect mediated primarily through the activation of muscarinic and histaminergic receptors while its spasmolytic effect was mediated possibly through $\mathrm{Ca}^{++}$antagonist pathway. Therefore, the report provides good information for the dual effectiveness of C. carandas in constipation and diarrhea [38].

\section{Antiemetic activity}

It was confirmed that the ethanolic extract of $C$. carandas fruit exhibited antiemetic activity against chick emetic model and showed a decrease in retches induced by copper sulfate pentahydrate given orally at $50 \mathrm{mg} / \mathrm{kg}$ body weight [39]. Phytochemical constituents of Carissa carandas Linn Phytochemical constituent analysis supporting with biological analysis is used for identification of active principles and their molecular targets from traditional medicine provides an enormous opportunity for drug development. So far many investigators have done research on phytochemical analysis to know the type of chemical class found in the different parts of $C$. carandas Linn.

Leaf: The methanol extract of $C$. carandas leaf demonstrated the presence of carbohydrate $[3,7,19,22]$ saponins $[7,19,22]$, unsaturated sterols $[7,22]$, alkaloids $[4,7,19,22]$, phenolics $[7,19]$ steroids, glycosides $[3,4,22]$, terpenoids $[3,22,40]$, tannins $[4,6,19,22,40]$, flavonoids $[3,4,6,22]$, proteins, oil/fats, and cardiac glycosides, but no reducing sugars [19]. The aqueous extract showed positive test for proteins, phenols, glycosides, flavonoids [23] and terpenoids [6,23]. Ethanolic extract of the leaf exhibited the presence of carbohydrates, proteins, amino acids, steroids, phenolics compounds and flavonoids [16].

Root: The phytochemical analysis of root extract showed the presence of alkaloids [6,14], flavonoids, saponins, cardiac glycosides, triterpenoids, phenolic compounds and tannins [6]. The ethanolic and aqueous extracts indicated the presence of steroids, flavonoids, tannins, alkaloid and glycosides [24]. The ethanolic extract indicated the presence of flavonoids, saponin, steroids, coumarin, alkaloids, carbohydrate, diterpenes, phytosterol, phenols and tannins whereas the aqueous extract showed the presence of flavonoids, saponin, steroids, proteins, amino acids, alkaloids, carbohydrate, diterpenes, phlobatannins, leucoanthocyanin, phytosterol, cardiac glycosides, chalcones, emodins, phenols and tannins. This indicated that aqueous solvent is more appropriate compared to ethanol to isolate different classes of phytochemical constituents from root of C. carandas [18].

Stem: phytochemical analysis from $C$. carandas stem extract showed the presence of sesquiterpene glucoside [6] and alkaloids [14].

Fruits: The extracts of fruit showed the presence of simple sugar and amino acids [14]. The presence of different chemical constituents like alkaloid, glycosides, saponin, terpenoids, flavonoids, tannins and steroids were experimentally approved in the mixture of water, chloroform and ethyl acetate extract of leave and fruit [15]. The ethanolic extracts of fruit and root revealed the presence of steroids, alkaloids, flavonoids, glycosides, reducing sugar, terpenoid, phenolic compounds and tannins [25]. Alkaloids, flavonoids, glycosides, reducing sugar, steroids, terpenoids and tannins are reported to be present in ethanolic extracts of unripe fruits and roots. Alkaloids, flavonoid, glycoside, terpenoid and tannins are present in ethyl acetate extract of unripe fruits and roots, while sterols, terpenoids and tannins are present in pet ether extract of unripe fruits and roots [21]. The methanol extract of fruit demonstrated the presence of reducing sugar, phenolic compounds, saponins, acids, protein, cardenolides [9], flavonoid, terpenes, steroids [9,26,28], alkaloids, glycosides, and tannins while, pet ether extract showed only carbohydrates and steroids $[26,28]$. 
Citation: Tesfaye T, Ravichadran YD (2018) Traditional Uses, Pharmacological Action and Phytochemical Analysis of Carissa carandas Linn.:A

\section{Isolation and characterization of compounds from Carissa carandas Linn.}

Carissa carandas has been used from immemorial time to yet traditionally to treat different human ailments. To know biologically active molecules, many investigators have done extraction to isolate and elucidate active chemical constituents and identified some compounds from different parts of $C$. carandas with different solvents.

Leaf: the leaf part of $C$. carandas was extracted with methanol and characterized some chemical constituents and found steroid derivative 20-hydroxypregnan 18-oic acid for their marked antioxidant and erythrocyte membrane stabilizing potential. Steroids exert their vital role against oxidative stress [22]. As mentioned in the Table 1 below, there are other compounds isolated from leaf such as: betulinic acid, $\beta$ sitosterol-3-O- $\beta$-D-glucopyranoside, oleanolic acid, and ursolic acid. Carandinol is one of the compounds isolated from leaf was exhibited significant in vitro cytotoxicity to every cell line tested (HeLa, PC-3 and $3 \mathrm{~T} 3$ ) and was relatively more toxic to human cervical cancer (HeLa) cell line [5]. Triterpenes, tannins [3,6,8-10,16,24,40] and carissic acid are compounds isolated from leaf part of $C$. carandas $[3,9,10,16,24,40]$.

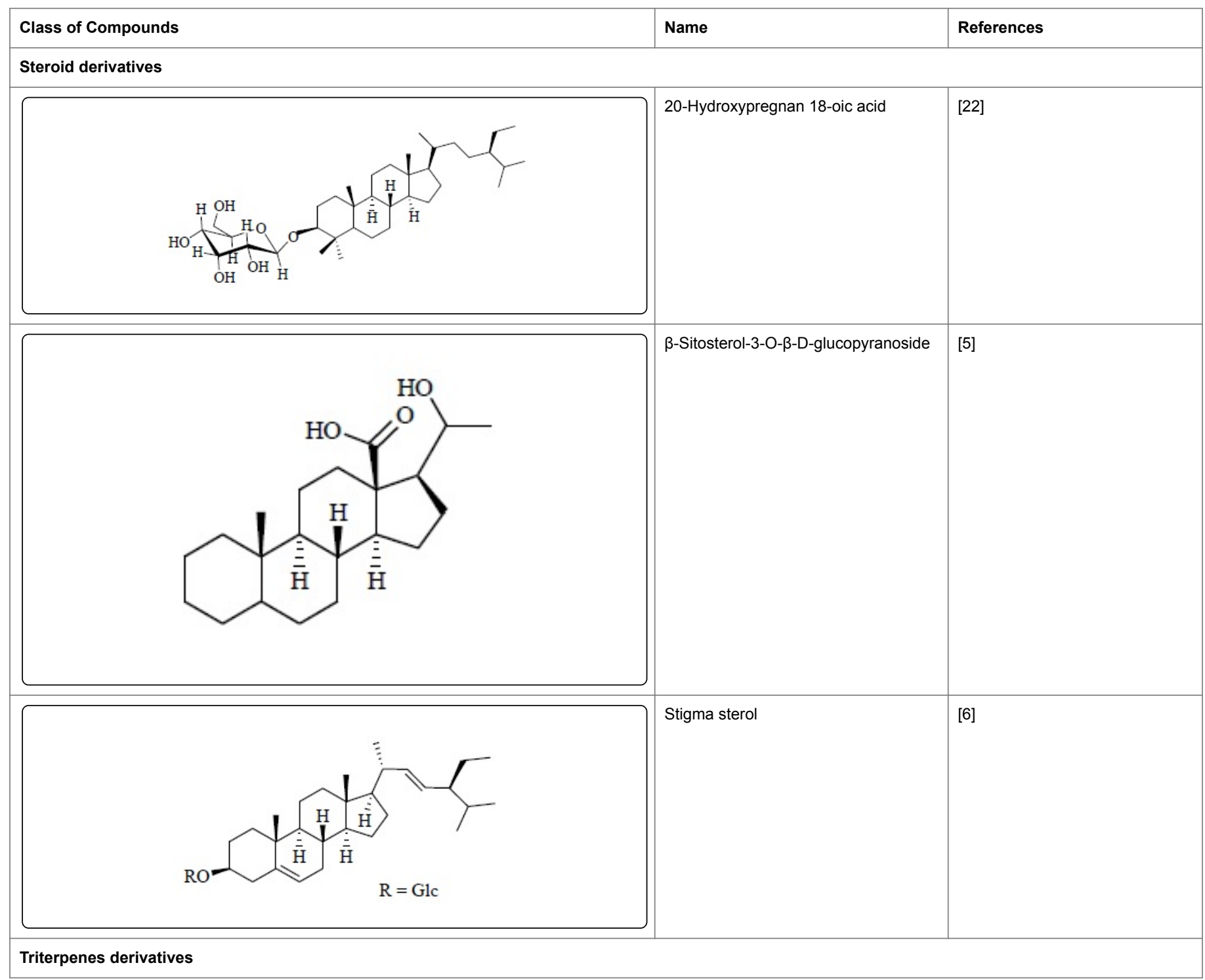


Citation: Tesfaye T, Ravichadran YD (2018) Traditional Uses, Pharmacological Action and Phytochemical Analysis of Carissa carandas Linn.:A Review. Nat Prod Chem Res 6: 334. doi:10.4172/2329-6836.1000334

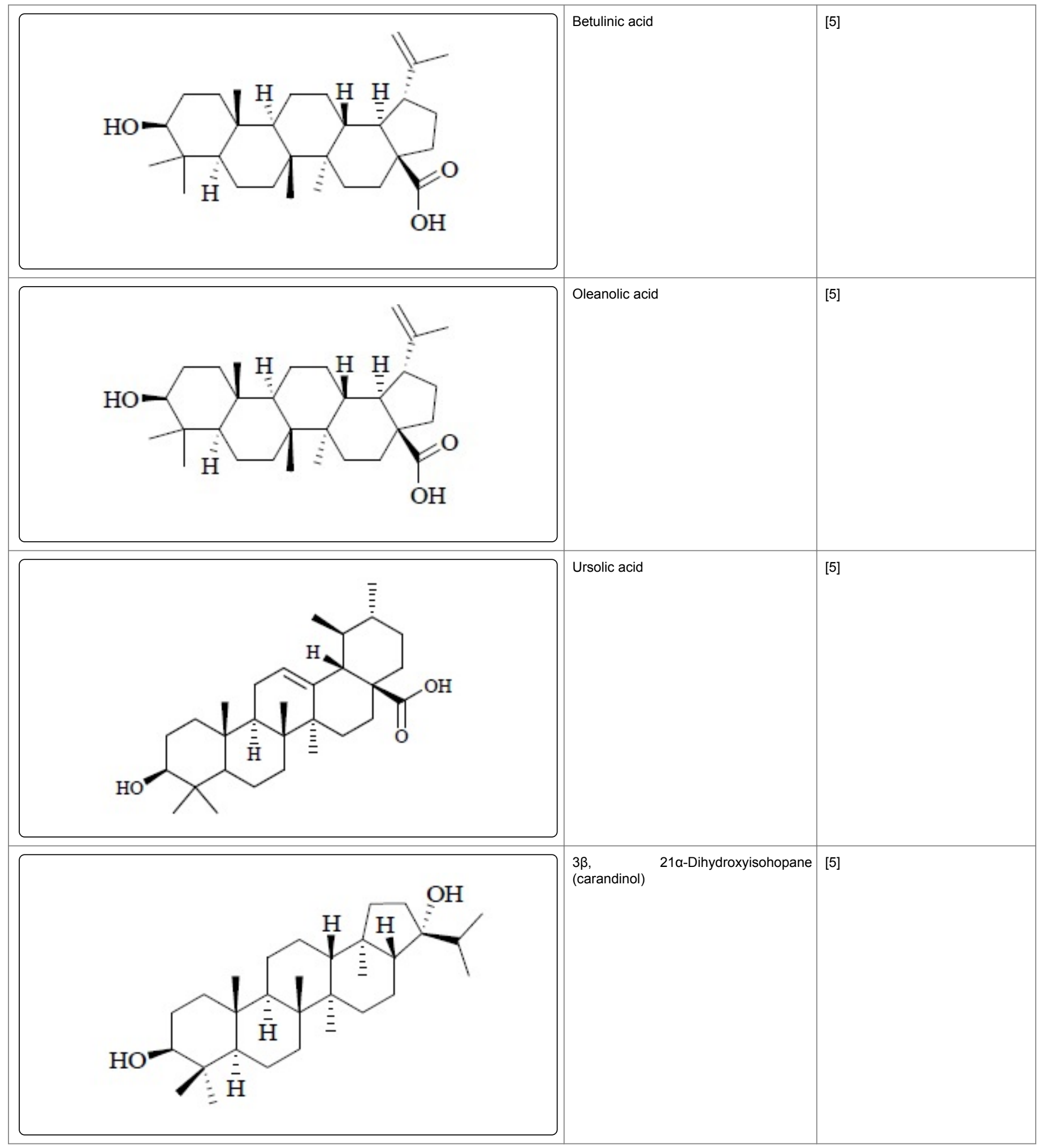


Citation: Tesfaye T, Ravichadran YD (2018) Traditional Uses, Pharmacological Action and Phytochemical Analysis of Carissa carandas Linn.:A Review. Nat Prod Chem Res 6: 334. doi:10.4172/2329-6836.1000334

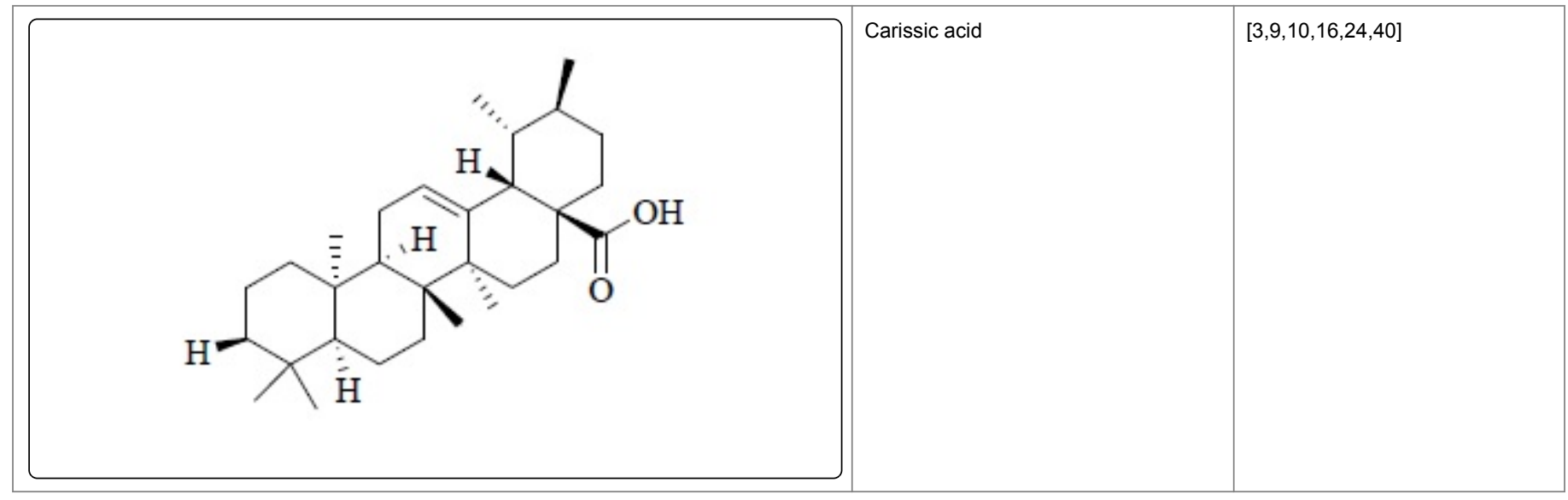

Table 1: Compounds isolated from leaf parts of Carissa carandas Linn.

Root: It was reported that some compounds were isolated from root part of $C$. carandas. The chemical constituents are ursolic acid, cholest-5-en-3 $\beta$-ol [22], $\beta$-sitosterol, lupeol [6,8,22], oleanolic acid $[6,22], \alpha$-amyrin $[6,8,22]$. Odoroside- $\mathrm{H}$ is one of the compounds which was isolated from root exhibited cardiotonic activity $[16,24]$. There are

\begin{tabular}{|l|l|l|l|}
\hline Class of Compounds & Name & References \\
\hline Alkaloid & [6,8] & \\
\hline Simple phenolic & 2-Acetylphenol & \\
\hline
\end{tabular}

other compounds isolated from roots such as: 2-acetylphenol $[6,8,10,24,40]$, sesquiterpenes (carissone, carindone), carinol, $[6,8,16,24,40], 16 \beta$-hydroxybetulinic acid, $\beta$-sitosterol glycoside, and des-Nmethylnoracronycine $[6,8]$ and their classes explained as Table 2 below. 
Citation: Tesfaye T, Ravichadran YD (2018) Traditional Uses, Pharmacological Action and Phytochemical Analysis of Carissa carandas Linn.:A Review. Nat Prod Chem Res 6: 334. doi:10.4172/2329-6836.1000334

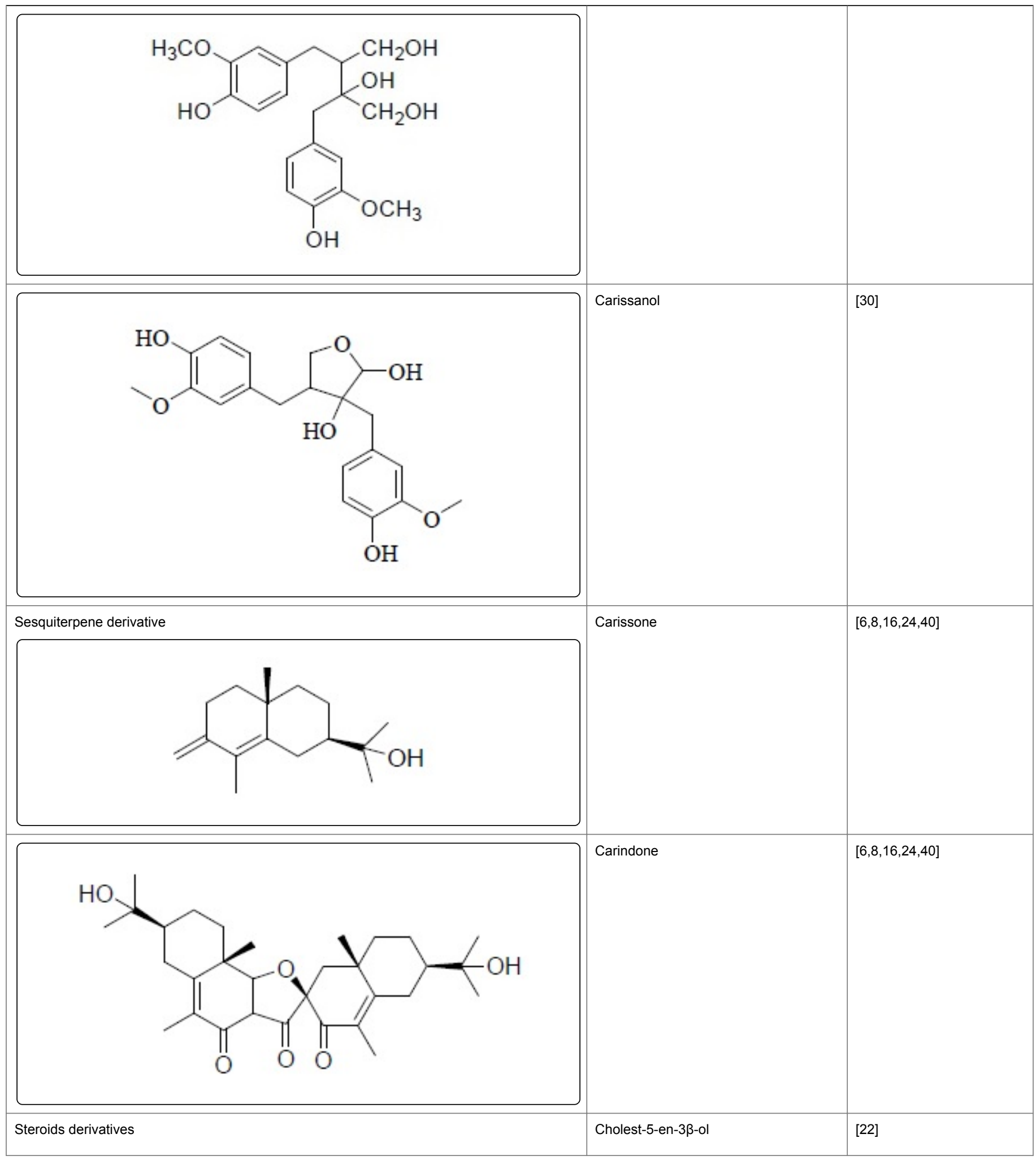


Citation: Tesfaye T, Ravichadran YD (2018) Traditional Uses, Pharmacological Action and Phytochemical Analysis of Carissa carandas Linn.:A Review. Nat Prod Chem Res 6: 334. doi:10.4172/2329-6836.1000334

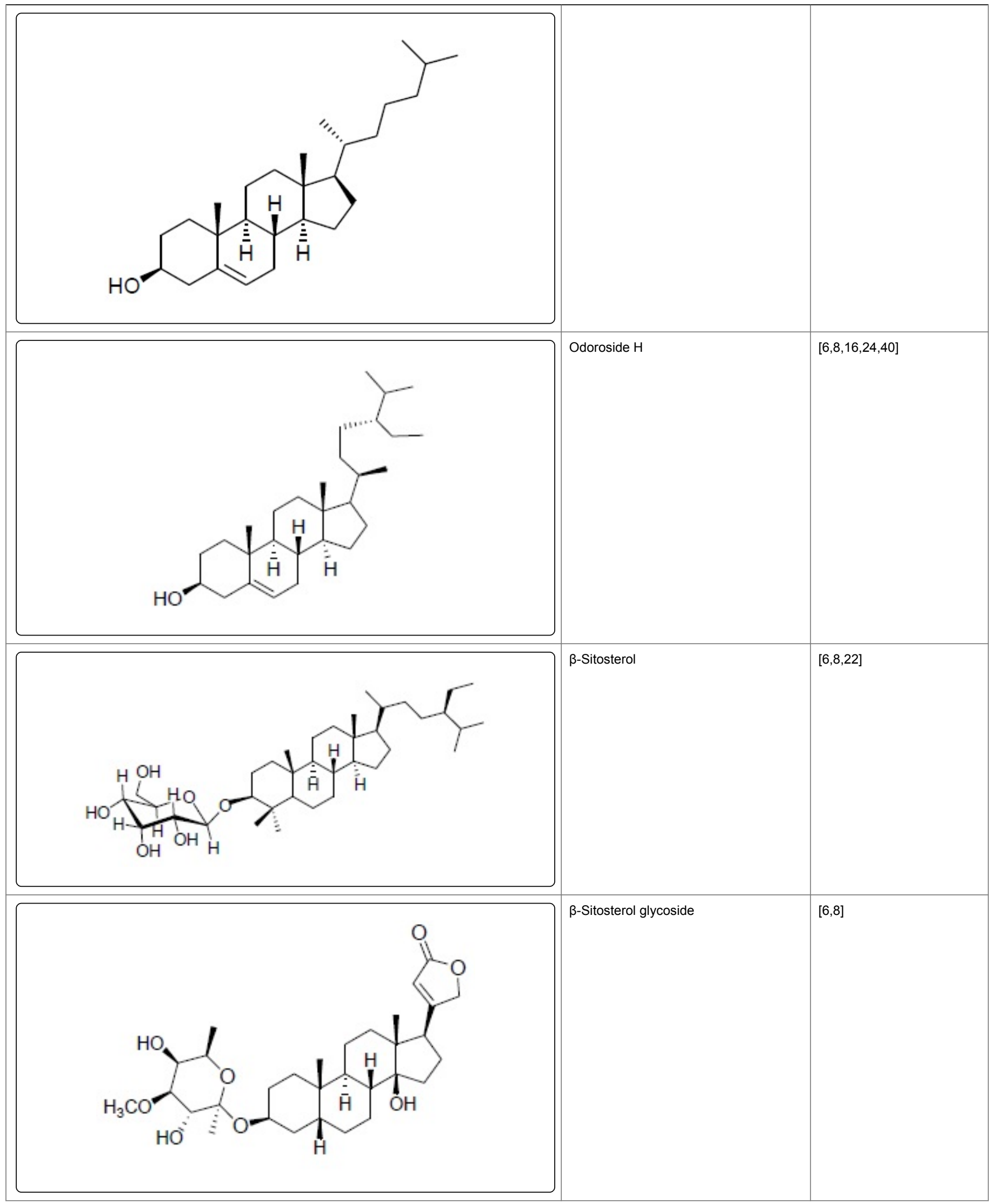


Citation: Tesfaye T, Ravichadran YD (2018) Traditional Uses, Pharmacological Action and Phytochemical Analysis of Carissa carandas Linn.:A Review. Nat Prod Chem Res 6: 334. doi:10.4172/2329-6836.1000334

Page 11 of 20

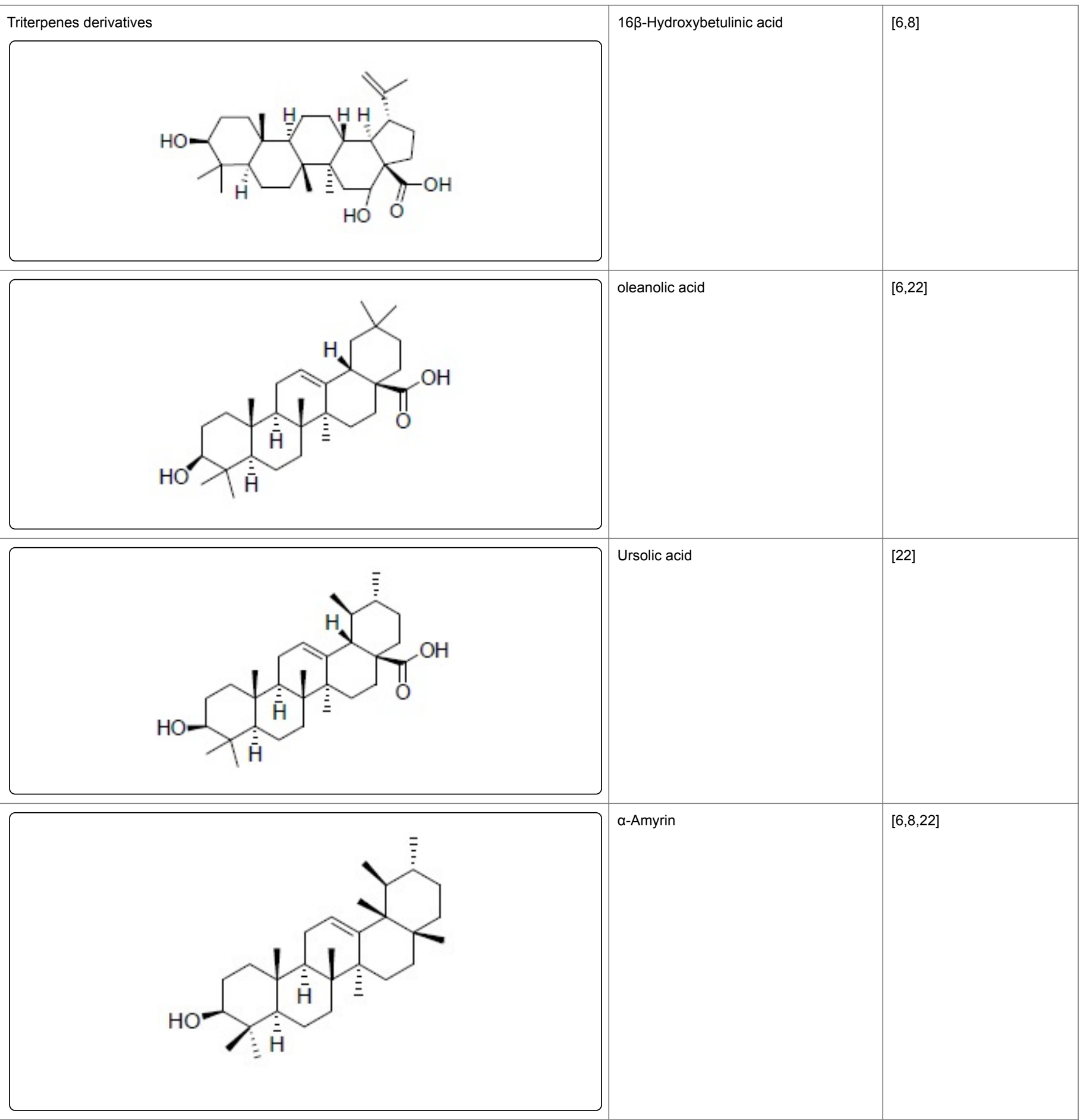


Citation: Tesfaye T, Ravichadran YD (2018) Traditional Uses, Pharmacological Action and Phytochemical Analysis of Carissa carandas Linn.:A

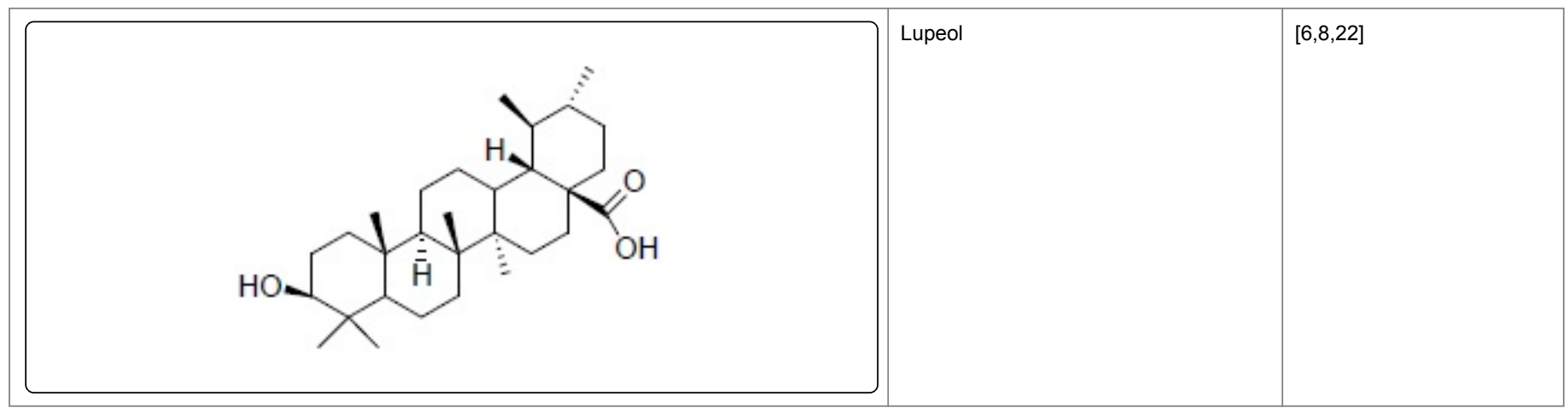

Table 2: Compounds isolated from root of Carissa carandas Linn.

Fruit: A fruit is the seed-bearing structure in flowering plants (also known as angiosperms) formed from the ovary after flowering. Fruits are the means by which angiosperms disseminate seeds. Edible fruits, in particular, have propagated with the movements of humans and animals in a symbiotic relationship as a means for seed dispersal and nutrition; in fact, humans and many animals have become dependent on fruits as a source of food.

In addition to use as edible fruit, the fruit of $C$. carandas has been reported for its anti-inflammatory activities [26]. The fruits part of this plant has been reported to contain a mixture of volatile principles like a novel triterpenic alcohol carissol, linalool, $\beta$-caryophyllene [3,8-10, $16,22,24,40]$, 2-phenyl ethanol, isoamyl alcohol, benzyl acetate $[3,10,16,24,40]$, epimer of $\alpha$-amyrin, lupeol [6,8-10], carissone, carissic acid, carindone, carinol, ascorbic acid, ursolic acid, $\beta$-sitosterol $[6,8,9]$, oxalic, tartaric, citric, malic, malonic and glycolic acids, glycine, alanine, phenyl alanine, serine, glucose, galactose [10]. Glucoside of odoroside- $\mathrm{H}$ is a new cardioactive substance and lanostenoloic acid which is used for adaptogenic activities are also isolated from fruits of C. carandas [9]. The classes of the listed compounds are indicated as Table 3 below.

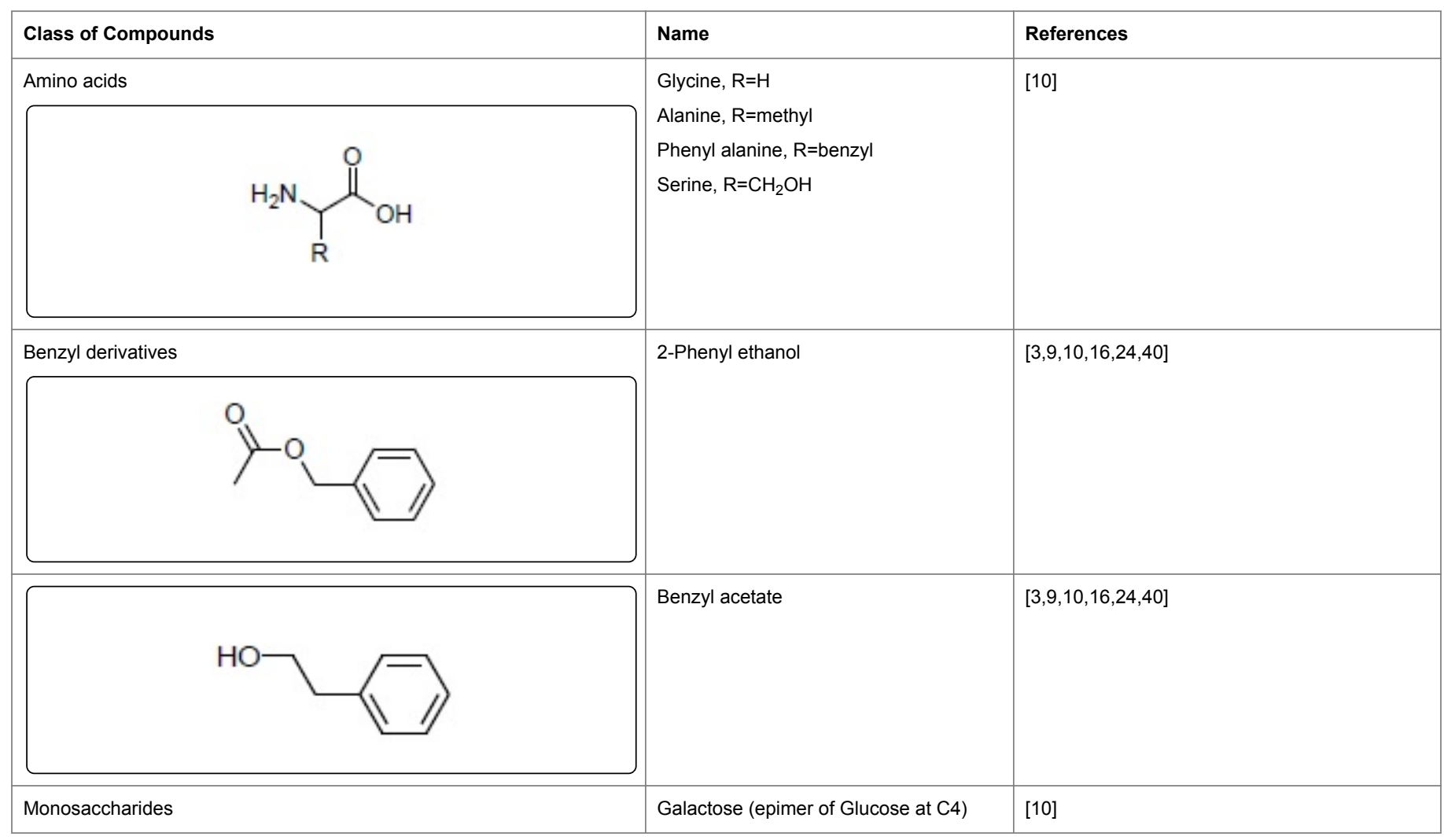


Citation: Tesfaye T, Ravichadran YD (2018) Traditional Uses, Pharmacological Action and Phytochemical Analysis of Carissa carandas Linn.:A Review. Nat Prod Chem Res 6: 334. doi:10.4172/2329-6836.1000334

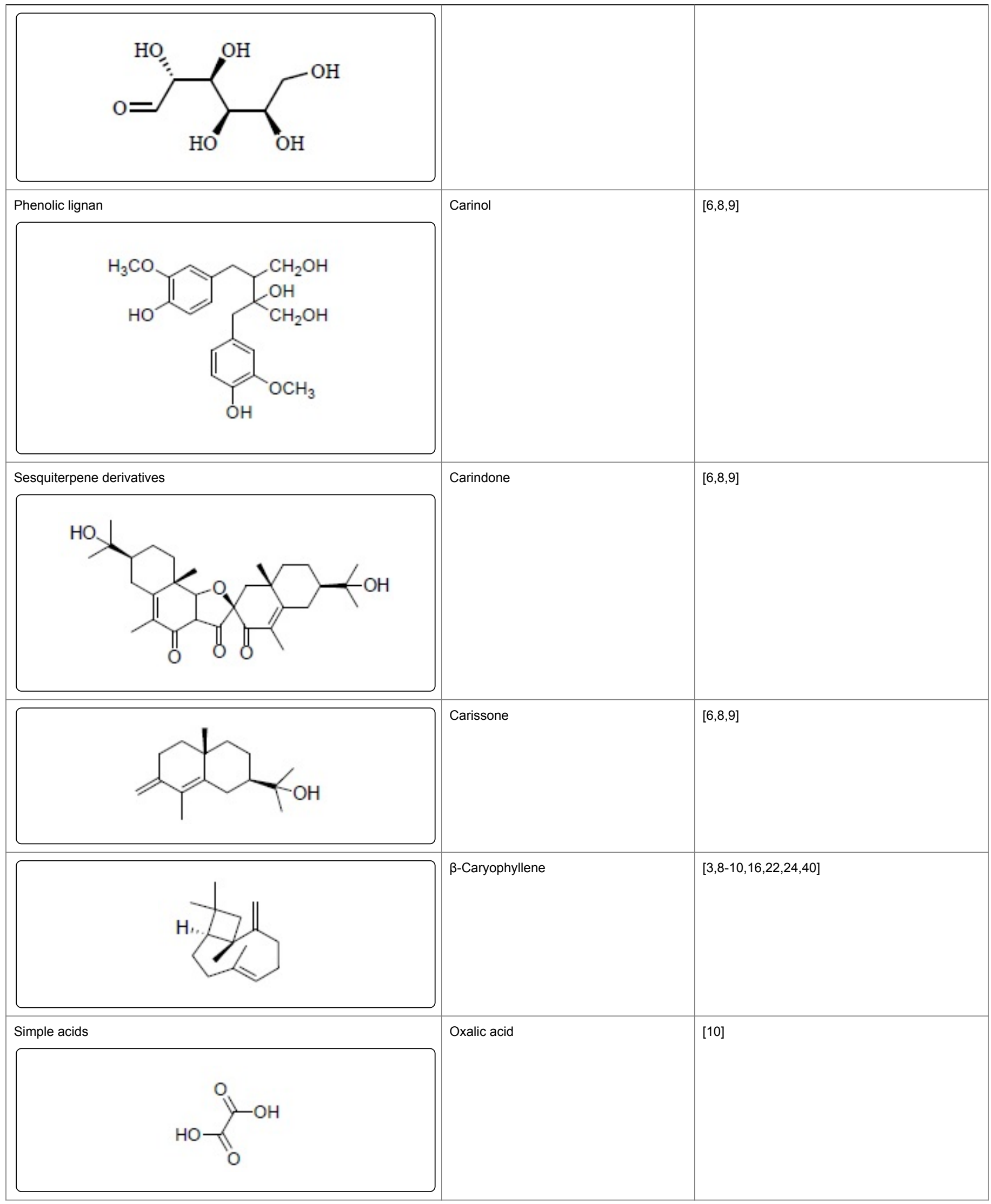


Citation: Tesfaye T, Ravichadran YD (2018) Traditional Uses, Pharmacological Action and Phytochemical Analysis of Carissa carandas Linn.:A Review. Nat Prod Chem Res 6: 334. doi:10.4172/2329-6836.1000334

Page 14 of 20

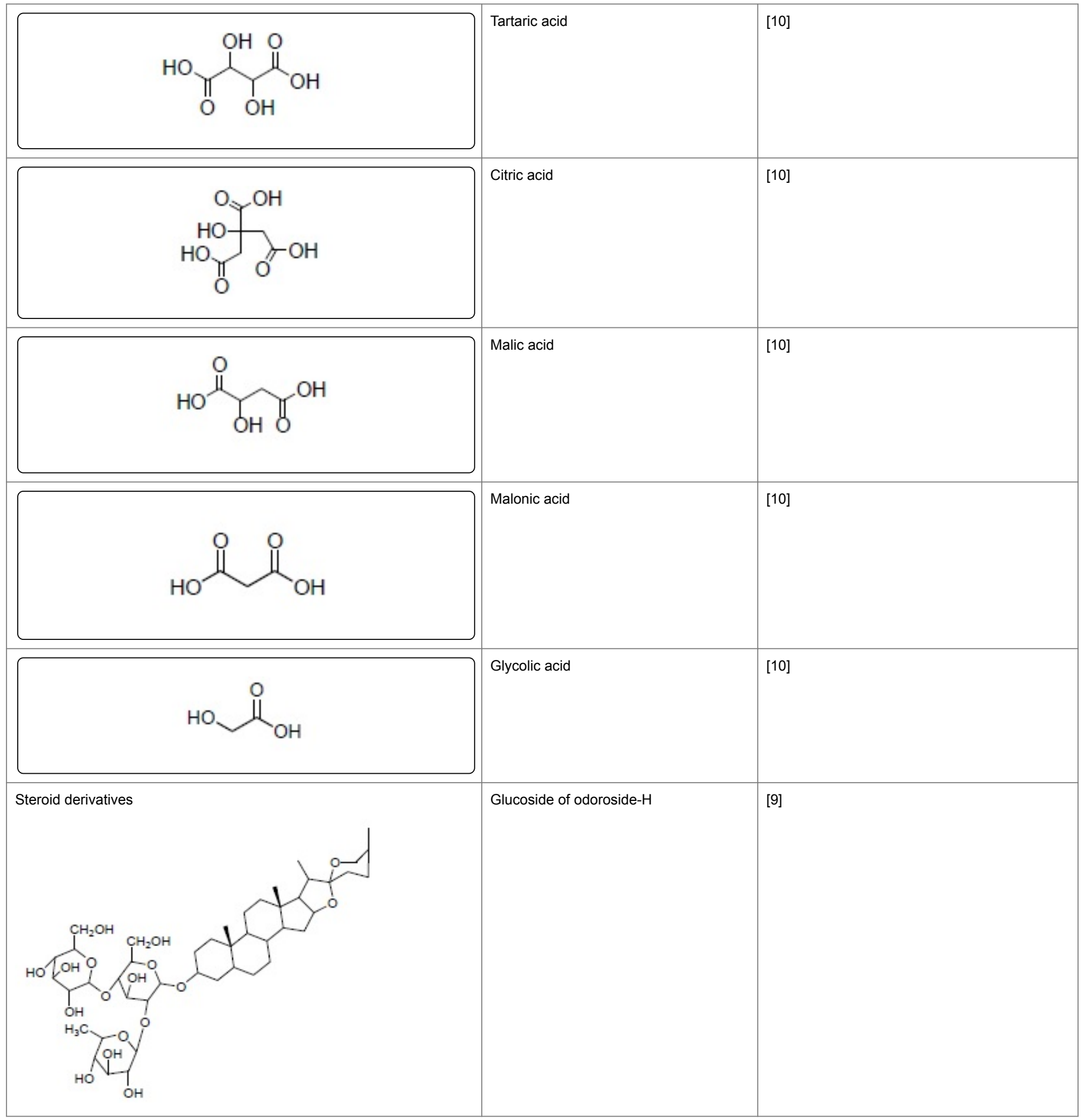


Citation: Tesfaye T, Ravichadran YD (2018) Traditional Uses, Pharmacological Action and Phytochemical Analysis of Carissa carandas Linn.:A Review. Nat Prod Chem Res 6: 334. doi:10.4172/2329-6836.1000334
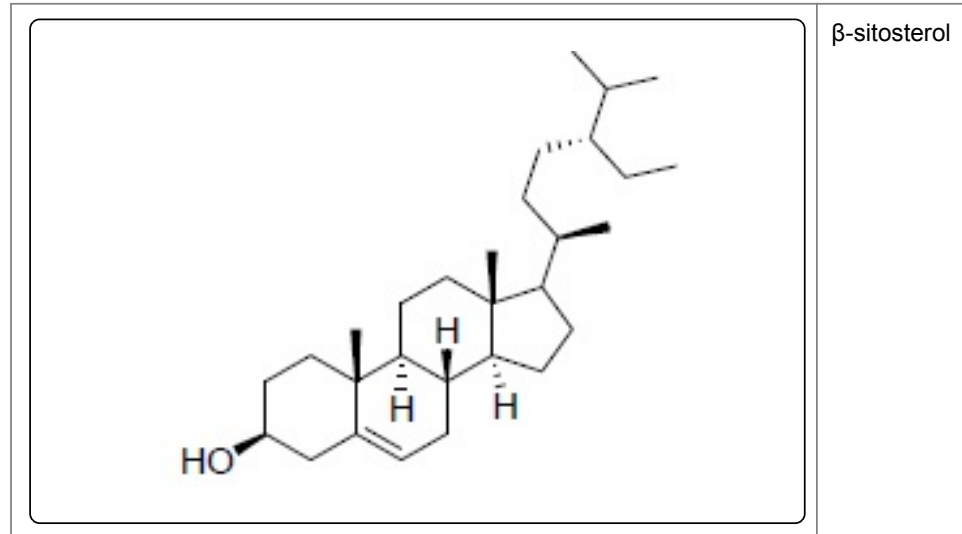

$[6,8,9]$

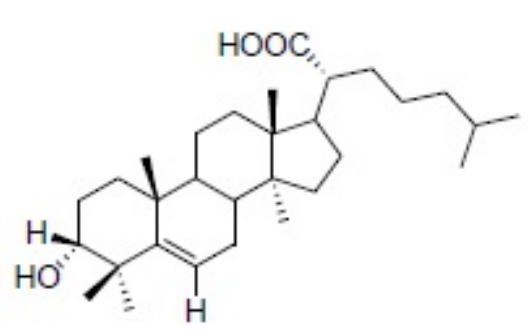

Lanostenoloic acid

[9]

Triterpenes derivatives

Lupeol

$[6,8-10]$


Carissic acid

$[6,8,9]$ 
Citation: Tesfaye T, Ravichadran YD (2018) Traditional Uses, Pharmacological Action and Phytochemical Analysis of Carissa carandas Linn.:A

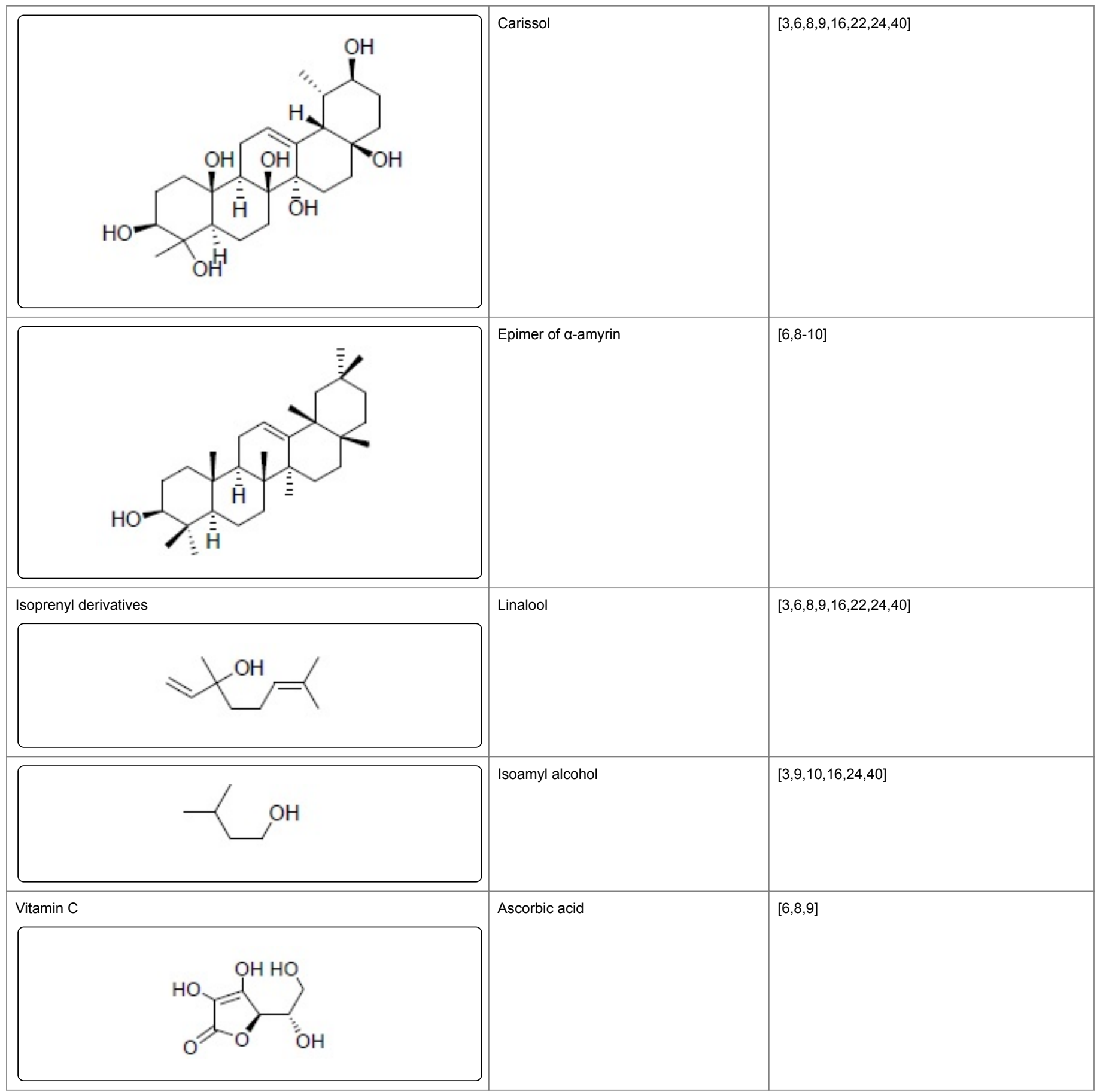

Table 3: Compounds isolated from fruit of Carissa carandas Linn.

Flowers: A flower, sometimes known as a bloom or blossom, is the reproductive structure found in plants that are floral (plants of the division Magnoliophyta, also called angiosperms). The biological function of a flower is to effect reproduction, usually by providing a mechanism for the union of sperm with eggs. Flowers may facilitate out crossing (fusion of sperm and eggs from different individuals in a population) or allow self-pollination (fusion of sperm and egg from the same flower). Many flowers have evolved to be attractive to animals, so as to cause them to be vectors for the transfer of pollen.

In addition to facilitating the reproduction of flowering plants, flowers have long been admired and used by humans to bring beauty to their environment, and also as objects of romance, ritual, religion, medicine and as a source of food. In addition to its beauty to environment, the flowers of $C$. carandas has good aroma of volatile organic compounds that attract animals. 
Citation: Tesfaye T, Ravichadran YD (2018) Traditional Uses, Pharmacological Action and Phytochemical Analysis of Carissa carandas Linn.:A Review. Nat Prod Chem Res 6: 334. doi:10.4172/2329-6836.1000334

Page 17 of 20

Most of the compounds isolated from flowers of C. carandas are volatile oil like myrcene, limonene, camphene, carene, dipentene, farnesol, nerolidol, $\alpha$-terpeneol, citronellal, $\beta$-ionone, nerylacetate, linalool and geranyl acetate [10]. The class and corresponding name is mentioned in the Table 4 below.

\begin{tabular}{|c|c|c|}
\hline Class of Compounds & Name & References \\
\hline & $\beta$-Ionone & [10] \\
\hline & a-Terpeneol & [10] \\
\hline & Myrcene & [10] \\
\hline & Limonene & [10] \\
\hline & Camphene & [10] \\
\hline & Carene & [10] \\
\hline & Citronellal & [10] \\
\hline
\end{tabular}


Citation: Tesfaye T, Ravichadran YD (2018) Traditional Uses, Pharmacological Action and Phytochemical Analysis of Carissa carandas Linn.:A Review. Nat Prod Chem Res 6: 334. doi:10.4172/2329-6836.1000334

Page 18 of 20

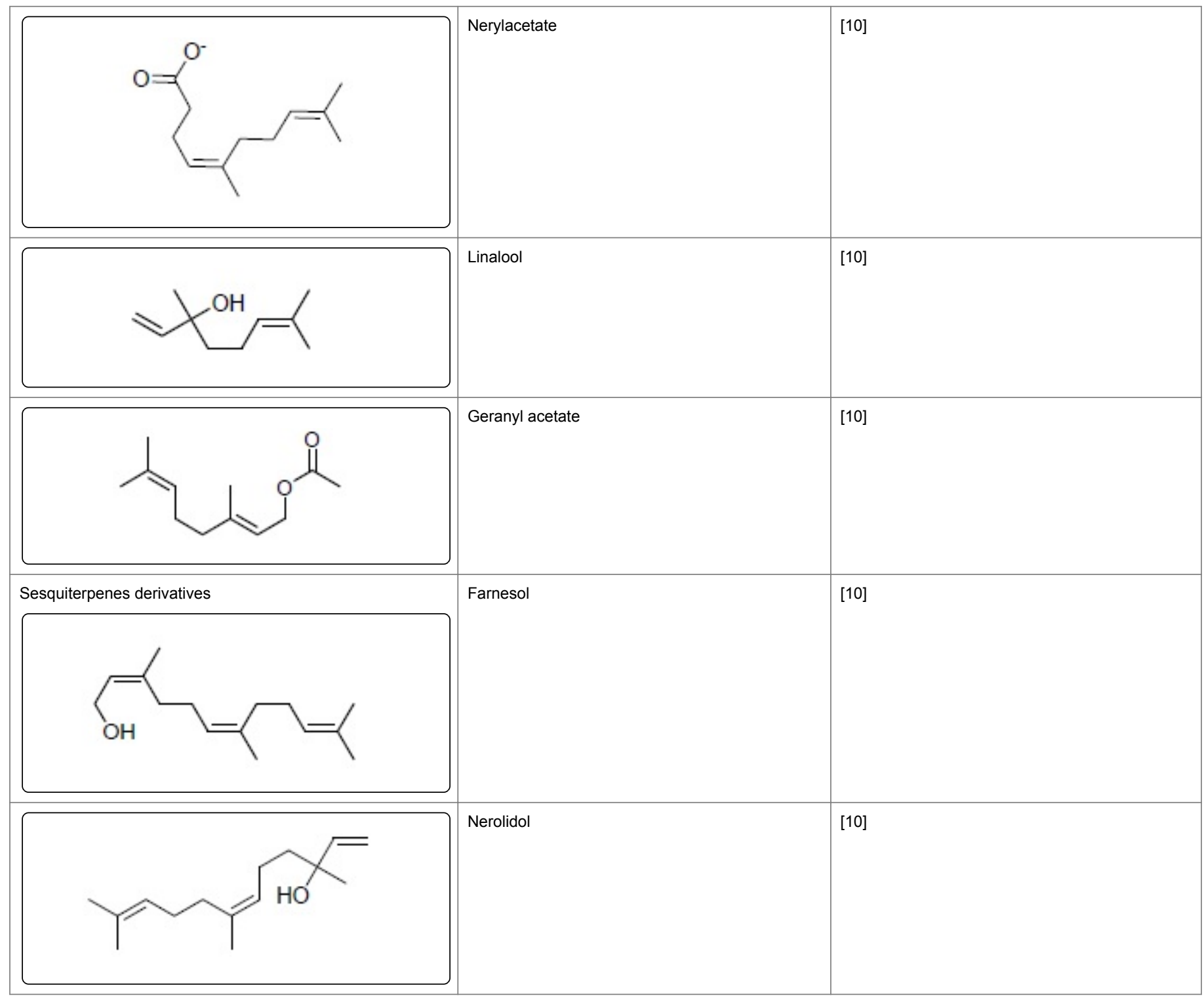

Table 4: Compounds isolated from flowers of Carissa carandas Linn.

\section{Conclusion}

Starting from immemorial time; peoples traditionally used herbs and plants to treat different human and animals ailments. This initiated scientists to investigate on traditional medicinal plants for biological activities by checking the crude extracts and fraction of extracts through bioassay and then isolating and characterizing the bioactive constituents from plant and organisms. From the review point of view, it has been revealed that the $C$. carandas (root, leaves, flowers and fruit) showed many traditional value, pharmacological uses and phytochemical constituents that are an excellent source of curing various ailments. To mention few, it has been used traditionally to treat scabies, intestinal worms, pruritus, biliousness, snake-bite/ poisoning, astringent, anemia, stomachache, diarrhea, rheumatism, earache, anthelmintic, female libido, hyperdipsia, anorexia, intermittent, mouth ulcer and sore throat, otalgia, and etc. It has been confirmed that it has pharmacological activities as hepatoprotective, neuropharmacological, anticancer, antioxidant, anticonvulsant, antiulcer, anthelmintic, analgesic, anti-inflammatory, cardiovascular, antinociceptive, anti-diabetic, anti-pyretic, cardiotonic, histamine releasing, DNA damage inhibition, constipation, anti-diarrheal, nutraceutical property, anti-hyperlipidemic, antibacterial, antiviral, cytotoxic potential and diuretic. Antioxidants play vital role in preventing the risk of so many diseases by interacting with free radicals. A number of active chemical constituents including phenolic compounds, flavonoids, phenolic acids, tannins, lignins, and alkaloids, vitamins etc., serve as useful antioxidants are present in the $C$. carandas particularly in the root followed by leaf. The results obtained in the present investigation are encouraging and can be used as an effective reference data for the standardization of $C$. carandas Linn. Even though its biological action approved by many scholars, only few biologically active compounds isolated from this plant. Almost all the investigators under reviewed papers used maceration and soxhlet 
method for extraction of all parts of the plant. The overall evaluation of this review shows that alcohol (methanol and ethanol) extraction followed by aqueous is the appropriate solvent for the extraction of $C$. carandas in order to get more phytochemical constituents. Further research has to be carried out to fractionate, purify and characterize the extracts, in order to find out the bioactive molecule which is responsible for human ailments by using different extraction techniques.

\section{References}

1. Fartyal M, Kumar P (2014) Bioactivity of crude extracts of Carissa carandas L. extracted in polar and non-polar solvents. International Journal of Engineering, Science and Innovative Technology 3: 186-191.

2. Agarwal T, Singh R, Shukla AD, Waris I (2012) In vitro study of antibacterial activity of Carissa carandas leaf extracts. Asian Journal of Plant Science and Research 2: 36-40.

3. Hati M, Jena BK, Kar S, Nayak AK (2014) Evaluation of antiinflammatory and anti-pyretic activity of Carissa carandas L. leaf extract in rats. Journal of Pharmaceutical, Chemical and Biological Sciences 1: 18-25.

4. Saha R, Hossain L, Bose U, Rahman AA (2011) Neuropharmacological and diuretic activities of Carissa carandas L. Leaf Pharmacology Online 2: 320-327.

5. Begum S, Syed SA, Siddiqui BS, Sattar SA, Choudhary MI (2013) Carandinol: First isohopane triterpene from the leaves of Carissa carandas L. and its cytotoxicity against cancer cell lines. Phytochemistry Letters 6: 91-95.

6. Singh A, Uppal GK (2015) A review on Carissa carandas phytochemistry, ethno-pharmacology, and micropropagation as conservation strategy. Asian Journal of Pharmaceutical and Clinical Research 8: 26-30.

7. Sadek YB, Choudhury N, Shahriar M (2013) Biological Investigations of the Leaf Extracts of Carissa carandas. International Journal of Pavement Research and Technology 5: 97-105.

8. Virmani R, Virmani T, Singh C, Sorout G, Gupta J (2017) Review on Hidden Potential of Natural Herb Carissa Carandas (Karonda). Research in Pharmacy and Health Sciences 3: 294-302.

9. Arif M, Kamal M, Jawaid T, Khalid M, Saini KS, et al. (2016) Review on Carissa carandas L. (Karonda): An exotic minor plant fruit with immense value in nutraceutical and pharmaceutical industries. Asian Journal of Biomedical and Pharmaceutical Sciences 6: 14-19.

10. Rana S, Prakash V, Sagar A (2016) Review on Medicinal and antioxidant properties of some medicinal plants. Journal of Drug Delivery and Therapeutics 6: 1-6.

11. Youngken HW (1950) Textbook of Pharmacognosy, 6th edn Philadelphia, PA: Blakiston.

12. Sumbul S, Ahmed SI (2012) Anti-hyperlipidemic Activity of Carissa carandas (Auct.) Leaves Extract in Egg Yolk Induced Hyperlipidemic Rats. Journal of Basic and Applied Sciences 8: 124-134.

13. Evans WC (1996) Trease and Evans' Pharmacognosy, 14th edn. London, WB: Saunders Company Ltd.

14. Inamullah SS, Rai J, Choudhary N, Sharma S (2013) A Review on Carissa Carandas L. International Journal of Pharmacy and Natural Medicines 1: 63-70.

15. Verma S, Chaudhary HS (2011) Effect of Carissa carandas against Clinically Pathogenic bacterial strains. Journal of Pharmacy Research 4: 3769-3771.

16. Saxena K, Irchhaiya R, Chagti KK (2016) Analytical and medicinal properties of ethanolic extract of leaves of Carissa carandas. World Journal of Pharmacy and Pharmaceutical Sciences 5: 1683-1690.

17. Sarma A, Sarmah P, Kashyap D, Dutta S, Mahanta M (2015) Antioxidant Activity and Nutraceutical Property of the Fruits of an Ethno-Medicinal Plant: Carissa carandas L. found in Brahmaputra Valley Agro-Climatic Condition. Journal of Pharmaceutical Sciences and Research 7: 55-57.
18. Rajaram S, Ashvin G (2013) Comparative studies of phytochemical screening of Carissa carandus L. Asian Journal of Plant Science and Research 3: 21-25.

19. Verma K, Shrivastava D, Kumar G (2015) Antioxidant activity and DNA damage inhibition in vitro by amethanolic extract of Carissa carandas (Apocynaceae) leaves. Journal of Taibah University for Science 9: 34-40.

20. Tolossa K, Debela E, Athanasiadou S, Tolera A, Gebeyehu GG, et al. (2013) Ethno-medicinal study of plants used for treatment of human and livestock ailments by traditional healers in South Omo, Southern Ethiopia. Journal of Ethnobiology and Ethnomedicine 9: 32.

21. Mishra CK, Shrivastava B, Sasmal D (2013) Pharmacognostical standardization and phytochemical identification of fruit and root of Carissa carandas L. International Journal of Pharmacy and Pharmaceutical Sciences 5: 347-350.

22. Bhushan SB, Ravindra HP (2017) Isolation, purification and characterization of antioxidative steroid derivative from methanolic extract of Carissa carandas L. leaves. Biocatalysis and Agricultural Biotechnology 10: 216-223.

23. Garg VK, Paliwa SK, Sharma S (2011) Analgesic and antipyretic activities of aqueous extract of leaves of Carissa carandas L. Pharmacology Online 1: 1109-1119.

24. Bhaskar VH, Balakrishnan N (2009) Analgesic, anti-inflammatory and antipyretic activities of Pergularia daemia and Carissa carandas. DARU 17: 168-174.

25. Mishra CK, Sasmal D (2015) In-Vivo evaluation of anti-diarrhoeal activity of Ethanolic fruit and root extracts of Carissa carandas L. (Apocynaceae). International Journal of Drug Development and Research 7: 216-221.

26. Anupama N, Madhumitha G, Rajesh KS (2014) Role of Dried Fruits of Carissa carandas as Anti-Inflammatory Agents and the Analysis of Phytochemical Constituents by GC-MS. BioMed Research International 6: 1-6.

27. Jayesh BD, Deepavali RT, Snehal NM, Archana RJ (2015) Carissa carandas L. Fruit extract ameliorates gentamicin-induced nephrotoxicity in rats via attenuation of oxidative stress. Journal of Acute Disease 5: 135-140.

28. Anupama N, Madhumitha G (2015) Potential health benefits of Carissa carandas dried fruit methanol extract. Journal of Chemical and Pharmaceutical Research 7: 841-847.

29. Oyvind MA, Kenneth RM (2006) Flavonoids, Chemistry, Biochemistry, and Applications. Taylor and Francis Group, LLC, CRC Press, pp: 2-3.

30. Kaunda JS, Zhang YJ (2017) The Genus Carissa: An Ethno pharmacological, Phytochemical and Pharmacological Review. Natural Products and Bioprospecting 7: 181-199.

31. Gaurav S, Navneet N, Sandeep R, Singh P, Amit P, et al. (2011) Effect of aqueous leaves extract of Carissa carandas L. on blood glucose levels of normoglycemic and alloxan induced diabetic wister rats. International Journal of Current Pharmaceutical Research 2: 65-67.

32. Itankar PR, Lokhande SJ, Verma PR, Arora SK, Sahu RA, et al. (2011) Antidiabetic potential of unripe Carissa carandas L. fruit extract. Journal of Ethnopharmacology 135: 430-433.

33. Middlemiss D, Watson SP (1994) A medicinal chemistry case study: An account of an angiotensin II antagonist drug discovery programme. Tetrahedron 50: 13049-13080.

34. Shamim S, Ahmad SI (2012) Pharmacodynamic study on acute hypotensive activities of Carissa carandas extract in normal rats. Pakistan Journal of Pharmaceutical Sciences 25: 577-582.

35. Arif M, Fareed S, Hussain T, Ali M (2013) Adaptogenic activity of lanostane triterpenoid isolated from Carissa carandas fruit against physically and chemically challenged experimental mice. Pharmacognosy Journal 5: 216-220.

36. Khushbu V, Divya S, Gaurav K (2015) Antioxidant activity and DNA damage inhibition in vitro by a methanolic extract of Carissa carandas (Apocynaceae) leaves. Journal of Taibah University for Science 9: 34-40. 
Citation: Tesfaye T, Ravichadran YD (2018) Traditional Uses, Pharmacological Action and Phytochemical Analysis of Carissa carandas Linn.:A Review. Nat Prod Chem Res 6: 334. doi:10.4172/2329-6836.1000334

Page 20 of 20

37. Islam MR, Rahman SM, Ahmed M, Das PR, Tabibul M, et al. (2012) Antinociceptive activity studies with methanol extract of Annona reticulata L. (Annonaceae) and Carissa carandas L. (Apocynaceae) leaves in Swiss albino mice. Advances in Natural and Applied Sciences 6: 1313-1318.

38. Mehmood MH, Anila N, Begum S, Syed SA, Siddiqui BS, et al. (2014) Pharmacological basis for the medicinal use of Carissa carandas in constipation and diarrhea. Journal of Ethnopharmacology 153: 359-367.

39. Mohtasheemul HM, Salman A, Ziauddin A, Iqbal A (2012) Antiemetic Activity of some Aromatic Plants. Pharmaceutical and Scientific Innovation 1: 47-49.
40. Maheshwari R, Sharma A, Verma D (2012) Mini review on Phytotherapeutic Significance of Karaunda. Bulletin of Environment, Pharmacology and Life Sciences 1: 34-36.

41. Parvin N (2018) Phytochemical screening, antinociceptive, anthelmintic and cytotoxicity studies of the leaves of Carissa carandas Linn. (Family: Apocynaceae). International Journal of Scientific Reports 4: 119-123.

42. Dhar G, Akther S, Sultana A, May U, Islam MM, et al. (2017) Effect of extraction solvents on phenolic contents and antioxidant capacities of Artocarpus chaplasha and Carissa carandas fruits from Bangladesh. Journal of Applied Biology and Biotechnology 5: 39-44. 